\title{
СТРАТЕГИЧЕСКИЕ АСПЕКТЫ В РАЗВИТИИ УПРАВЛЕНИЯ ПРОЕКТАМИ В УСЛОВИЯХ ЦИФРОВОЙ ТРАНСФОРМАЦИИ
}

\section{STRATEGIC ASPECTS \\ IN THE DEVELOPMENT OF PROJECT \\ MANAGEMENT IN THE CONDITIONS OF DIGITAL TRANSFORMATION}

\section{A. Lukyanova}

Summary. The relevance of the article is associated with the importance of strategic management, which is identified with the process that ensures the survival and development of the organization. The article defines the specifics of the strategic aspects of this process in relation to individual projects in the context of digital transformation. It is shown that the strategic tasks of project management include: creating and updating the selected elements of the project strategy, supply chain management, ensuring customer satisfaction and maintaining the key parameters of the project.

Keywords: digitalization, strategic management, resources, project, strategic decision.

\author{
Лукьянова Анна Васильевна \\ Д.э.н., дочент, Финансовый университет при \\ Правительстве РФ, Москва \\ avlukyanova@yandex.ru
}

Аннотация. Актуальность статьи связана с важностью стратегического управления, которое отождествляется с процессом, обеспечивающим развитие любой организации. В статье определена специфика стратегических аспектов этого процесса применительно к отдельным проектам в условиях цифровой трансформации. Показано, что стратегические задачи управления проектами включают: создание и обновление выбранных элементов стратегии проекта, управление цепочкой поставок, обеспечение удовлетворенности клиентов и сохранение ключевых параметров проекта.

Ключевые слова: цифровизация, стратегическое управление, ресурсы, проект, стратегическое решение.

зованию искусственного интеллекта в анализе данных [1].

На протяжении многих лет проекты рассматривались как часть операционной деятельности компании, которая отвечала за реализацию стратегии компании. Концепцию стратегии принято использовать для постоянных субъектов, то есть тех, чьи особенности определены теориями предприятия. Такой подход явился результатом целенаправленного восприятия проекта как инструмента, позволяющего производить продукт, которому были выделены ограниченные временные и стоимостные ресурсы, и были определены результаты в форме объема или качества. Изменение восприятия проекта, указание на его характер как временную организацию, позволило более широко использовать концепцию стратегического управления. В условиях высокой сложности реализуемых проектов или расширения деятельности предприятий нет возможности и необходимости полностью зависеть от проекта от организации. Поэтому были приняты во внимание децентрализация управления в среде проектирования. Предполагалось, что даже в проектных компаниях должен быть обеспечен определенный уровень автономности проекта, понимаемый как степень, в которой он может развиваться самостоятельно, когда команда проекта 
принимает ключевые решения для его реализации без необходимости получения одобрения от руководства организации [4].

Одним из элементов стратегической важности управления проектами является правильный подбор участников проекта или обеспечение соответствующей системы управления проектом. Полагаем, что задачи, связанные с формированием цепочки поставок, здесь носят стратегический характер. В основном они включают в себя выбор объема аутсорсинга, ключевых деловых партнеров, а затем построение устойчивых взаимоотношений, благодаря которым дальнейшее сотрудничество станет возможным не только при реализации последующих проектов или перспективы портфеля проектов, но и на последующих этапах жизненного цикла проекта, в том числе при перспективе отдельного проекта [2].

Эволюция восприятия проекта и управления им позволила шире использовать достижения теории стратегического управления, значительно выходя за рамки классического проектного треугольника, на основе таких критериев как бюджет, время, качество / объем распространяясь на оценку точки зрения заказчика или подрядчика и получения ими удовлетворительного результата. Учет условий проектной среды, включая потребности головной организации и других заинтересованных сторон, является наглядным доказательством этого. Однако в литературе по теме управления в проектной среде по-прежнему мало исследований, связанных со стратегическим управлением отдельным проектом.

Наиболее общепринятые исследовательские точки зрения относятся к $[2,5]$ :

- управлению проектами как концепции функционирования проектных организаций,

- портфелю проектов как способу обеспечения успеха организации, достижению ее стратегических целей,

- программе как методу внесения стратегических изменений в организацию,

- проекту как инструменту для реализации постоянной стратегии организации, включая стратегию проекта как элемент постоянной стратегии организации,

- стратегию проекта как набор элементов, позволяющих достичь конкурентного преимущества и лучших результатов проекта,

- совершенствованию инструментов, поддерживающих стратегическое управление проектами.

Из вышеперечисленных направлений наиболее близкими к теме статьи являются вопросы стратегии проекта как способа достижения его успеха и совершенствования вспомогательных инструментов за счет цифровых технологий. Они указывают на возможность адаптации стратегического мышления к уровню отдельного проекта. Исследования в этой области касаются, в частности, делегирования ответственности, также связанной с принятием стратегических решений руководителем проекта. Его роль в стратегическом управлении проектами может включать, среди прочего, управленческое решение о применении выбранной стратегии на этапе реализации, а также выбора цифровых технологий и информационных систем, необходимых для успешного его окончания.

На обоснованность применения стратегической перспективы к отдельному проекту также указывают результаты исследования желаемых компетенций руководителя проекта. Они определяют необходимость для лидера применять стратегическую перспективу в управлении, которая требует, среди прочего, способность определять видение проекта в отношении развития конечного продукта, а также позиционировать его, использовать стратегические возможности, которые он дает, а также отслеживать связанные с этим риски.

Адаптация стратегического мышления от теории постоянной организации к временной организации должна учитывать специфику проекта, в первую очередь связанную с конечным периодом продолжительности проекта и установленной даты завершения, его организационно-правовую форму, в некоторых случаях ее отсутствие, или владение используемыми ресурсами, где чаще всего их владельцем является сама организация, а не проектное подразделение также в значительной степени используется аутсорсинг. Исходя из этого, можно указать, что предметом теории стратегического управления проектами являются вопросы планирования и реализации проекта по отношению к его продукту. Наиболее важным в развитии этой тенденции является применение субъективного, когда проект рассматривается как временная организация, реляционного в случае, если проект является ключевым элементом цепочки поставок или финансового контроля при применении агентской теории и теория трансакционных издержек.

Таким образом, стратегические аспекты управления проектами в условиях цифровой трансформации включают в себя ключевые внутренние аспекты, связанные c:

- производством продукта с учетом плана-графика, размера прибыли, плана платежей, рисков и возможностей и т.д.,

- управлением цепочкой поставок, включая отношения с клиентами. 
Ответственность за стратегическое управление проектами проявляется не в организационной структуре каждого проекта, а скорее в случае проектов: более крупных с точки зрения стоимости, более сложных и инновационных с точки зрения объема и типа рабо- ты или сложности продукта, или долгосрочных с точки зрения жизненного цикла проекта. В рамках создания стратегии проекта важно определить ответственность за определение продукта и определение критериев успеха / неудачи.

\section{ЛИТЕРАТУРА}

1. Езеева И.Р., Гайрбекова Р.С. Некоторые аспекты совершенствования методов управления инновационными проектами в условиях цифровизации экономики // Естественно-гуманитарные исследования. 2020. № 5 (31). С. 117-121.

2. Каралидзе Г.В., Залучёнова 0.М. Система управления проектами как инструмент управления реализацией стратегических целей // Austrian Journal of Humanities and Social Sciences. 2021. № 1-2. C. 44-52.

3. Кустова Ю.Ю. Место управления проектами в системе стратегического управления компании // Экономика и бизнес: теория и практика. 2020. № 5-3. C. 58-61.

4. Лубянская Э.Б. Сущность и содержание стратегического управления инновационными проектами предприятия // ЭКОНОМИНФ0. 2019. № 1. С. 22-26.

5. Сулоева С.Б., Абушова Е.Е., Бурова Е.В. Стратегический управленческий учет в системе управления проектами на промышленных предприятиях // Организатор производства. 2019. № 1. С. 43-54.

○ Лукьянова Анна Васильевна ( avlukyanova@yandex.ru ).

Журнал «Современная наука: актуальные проблемы теории и практики»

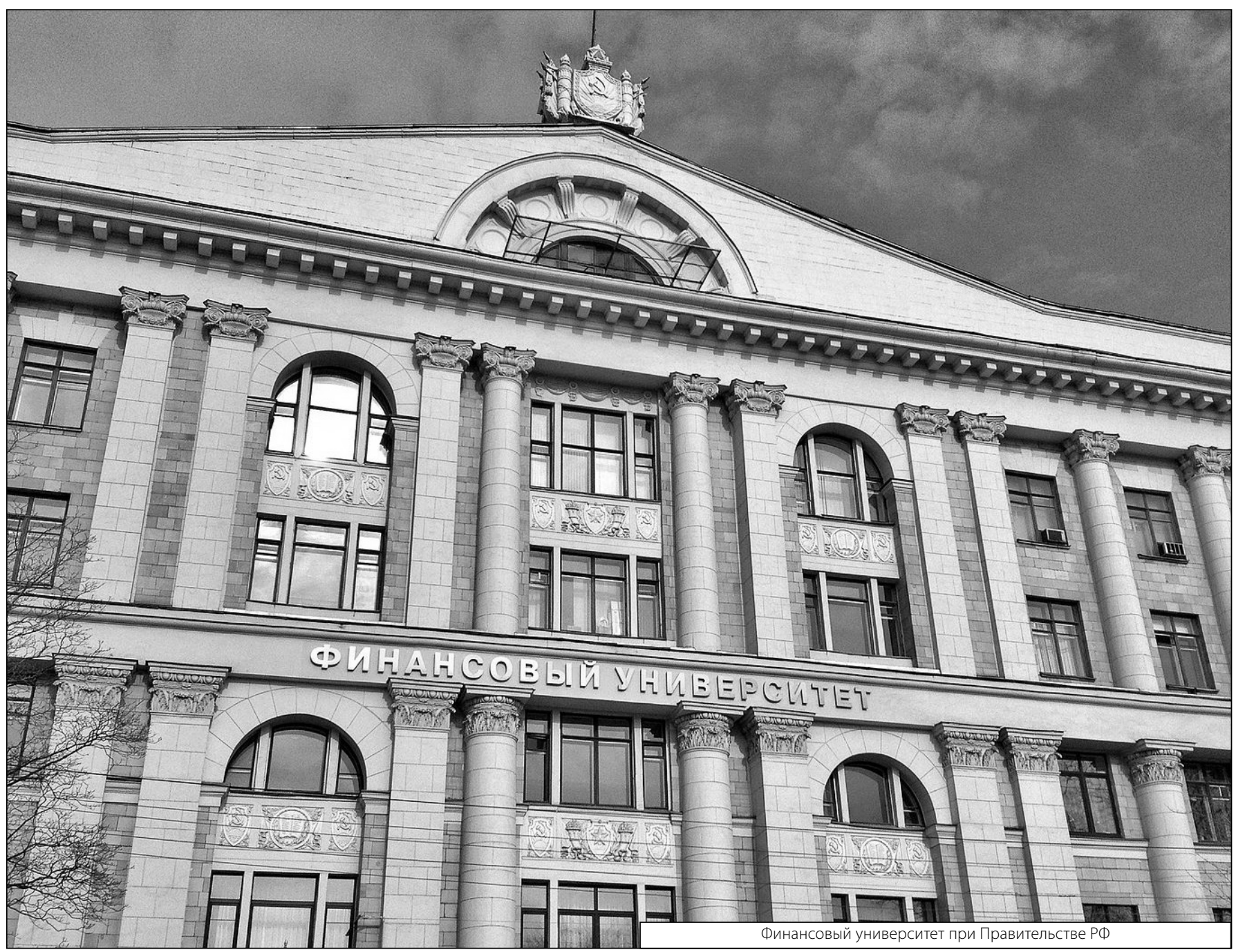

